\title{
Acoustic-Mechanical Responses of Intact and Flaw-Contained Rock Deformation under Uniaxial Compression: A Comparison
}

\author{
Gui-Lin Wang, ${ }^{1,2}$ Liang Zhang $\mathbb{D},^{2}$ Zhen Wang, ${ }^{2}$ Jian-Zhi Zhang, ${ }^{2}$ Fan Sun, \\ and Pei-Yong Qiu ${ }^{3}$ \\ ${ }^{1}$ National Joint Engineering Research Center of Geohazards Prevention in the Reservior Areas (Chongqing), \\ Chongqing 400045, China \\ ${ }^{2}$ School of Civil Engineering, Chongqing University, Chongqing 400045, China \\ ${ }^{3}$ Department of Civil, Geological and Mining Engineering, Ecole Polytechnique de Montreal, \\ Research Institute on Mines and the Environment (RIME UQAT-Polytechnique), Montreal, Canada QC H3C 3A7 \\ Correspondence should be addressed to Liang Zhang; 963082640@qq.com
}

Received 15 January 2019; Revised 12 April 2019; Accepted 22 April 2019; Published 13 May 2019

Academic Editor: José Aguiar

Copyright (c) 2019 Gui-Lin Wang et al. This is an open access article distributed under the Creative Commons Attribution License, which permits unrestricted use, distribution, and reproduction in any medium, provided the original work is properly cited.

\begin{abstract}
The study of the mechanical properties and cracking behaviors of jointed rock masses is important in rock engineering projects. In the present study, a series of uniaxial compression experiments were conducted on intact rock, and rock masses with single or double preexisting flaws, and then the strength, deformability, and fracture behavior of samples are investigated. Moreover, photographic monitoring technique and emission monitoring technique are introduced to explore the fracturing mode and the acoustic emission (AE) evolution characteristic of fractured rock during the whole loading process. The obtained results show that the preexisting flaw has a strong influence on the mechanical properties, fracture behavior, and AE characteristic of sandstone specimens. In detail, the stress-strain curves show that no significant stress jump occurs at prepeak and postpeak points for intact sandstone specimens; however, the flaw-contained sandstone specimens exhibit distinct stress jump during the entire loading process. Meanwhile, the strength parameters of the the rock specimen is obviously weakened by the preexisting fissures, and the uniaxial compression strength of rock specimens generally decreases with the increase in the number of preexisting fissure as well as the peak strain and the elastic modulus. The failure modes of intact and flaw-contained sandstone specimens exhibit the splitting failure and the mixed failure modes of shear and tension, respectively. Similarly, the maximum AE counts and AE energy both decrease with the increasing number of preexisting flaw. The present research can enhance the understanding of mechanical properties, cracking behaviors, and failure mechanism of jointed rock mass.
\end{abstract}

\section{Introduction}

Faults, joints, and fractures are widely distributed in natural rocks, and the existence of these discontinuous surfaces greatly deteriorates the strength and deformability behavior of rock masses [1-5]. Under the effect of dead and live load, primary fractures initiate, propagate, and coalesce with each other, which results in a number of geological hazards, such as landslide, instability of slope, and tunnel face. Therefore, better understanding of the mechanical properties and failure mechanism of jointed rock mass is pressing.
Up to now, a lot of studies have been performed on strength, deformation, and cracking behaviors of rock material under axial compression. Mechanical properties and failure mechanism of intact rock were investigated. Kong and Shang [6] proposed a novel method to estimate uniaxial compression strength (UCS) of rock according to the index test on uniform and homogeneous brick samples. Isah et al. [7] introduced a new multichannel fiber Bragg grating sensors (MC-FBGs) to investigate deformation properties of intact rock samples. Li et al. [8] studied the deformation and cracking characteristics of rock salt under 
triaxial compression by ultrasonic waves and $\mathrm{AE}$ techniques.

Considering the influence of discontinuity on properties of rock mass, failure process regarding flaw-contained rock specimens under compression was experimentally and numerically studied by numerous scholars. It was found that mechanical behavior and failure modes of flaw-contained rock are strongly affected by the forms and properties of preexisting flaws. Previous studies on precracked material mainly consisted of the following three categories, namely, experimental tests on rock-like materials, numerical simulation on model specimens, and experimental tests on original rocks. Due to the high efficiency and low cost, rocklike materials have widely been used in many experiments [9-15]. According to uniaxial compression tests for rock-like materials containing three parallel frictional flaws, Wong et al. [16] found that the uniaxial compression strength of the specimens depended on the actual number of preexisting flaws involved in the coalescence. Meanwhile, crack coalescence process depended on the flaw arrangement and the frictional coefficient on the flaw surface. Park and Bobet [17] investigated the crack propagation and coalescence from frictional discontinuities through prismatic gypsum specimens with three preexisting flaws. Three different types of cracks (i.e.,wing cracks, coplanar shear, and oblique shear cracks) and seven coalescence types were observed. Liu et al. [18] and Huang et al. [19, 20] studied the mechanical properties and cracking behavior of prefissured specimens (two parallel and unparallel fissures). After that, Cao et al. [21] also found that uniaxial compression strength and elastic modulus of a rock-like specimen simultaneously reach the minimum when the inclination angle is 45 degree. Uniaxial compression strength and elastic modulus decreased with increasing joint distance. With the development of computer science, numerical simulation had been employed to study the failure mechanism of rock. Yang et al. [22] and Manouchehrian et al. [23] adopted PFC2D to study the cracking behavior of fractured rock. Simulation results showed that the crack initiation angle became steeper due to the increase of confinement stress. The effect of the ligament length and the flaw inclination angle on the coalescence pattern were with AUTODYN studied by Wong and $\mathrm{Li}$ $[24,25]$, and the effect of geometric parameters of joints, crack initiation, growth, and coalescence on the failure modes of fractured rock were studied by Bahaaddini et al. [26] and Wang et al. [27] through PFC3D and RFPA3D, respectively. Marji et al. [28-30] used a modified displacement discontinuity method to analyze the quasi-static crack branching, hydraulic fracturing, and breaking process of precracked Brazilian disc specimens in brittle solids. However, the failure processes of rock-like materials and simulation model may be different from that of natural rocks [31]. Recently, many experiments were performed on original rocks to simulate the cracking process in a more realistic way. For example, Morgan et al. [32] and Lu et al. [33] carried out uniaxial compression tests on sandstone and granite to investigate the influence of the flaw geometry, crack coalescence on failure behavior of rock. In the latest studies, Yang et al. [34] investigated the failure mechanism of brine-saturated sandstone containing two preexisting flaws under different confining pressures.

As acoustic signals are strongly correlated with cracking process of rock materials $[35,36]$, recently, acoustic signal monitoring techniques have been employed in corresponding laboratory tests. Yang et al. [37] studied the strength and deformation behaviors of red sandstone material containing two unparallel fissures through photographic monitoring and $\mathrm{AE}$ monitoring techniques. In uniaxial compression tests on dry and saturated basalt columnar joints, Liu et al. [38] determined the location of cracks by AE events. Zhu et al. [39, 40] studied the mechanical properties and fracture evolution of prismatic flawed sandstone based on AE and digital image correlation (DIC) techniques, and the mechanical behavior and surface strain fields obtained with experiments showed good agreement with the data from the internal AE signals.

However, the influences of the number of preexisting flaws on the mechanical behavior, fracture mechanism, and failure mode under uniaxial compressive loads have not systematically been investigated for the original rock material. Besides, the effect of the number of preexisting flaws on $\mathrm{AE}$ events and the comparison of $\mathrm{AE}$ evolution characteristics between intact and flaw-contained rocks have not been reported yet. In the present study, a series of uniaxial compression tests were conducted on intact rocks and rocks containing different number of flaws to simulate the cracking processes of sandstone. Besides, photographic and emission monitoring technique were introduced to obtain the images and the AE evolution characteristic. Acoustic and mechanic responses of intact and flaw-contained rock were compared. Therefore, the effects of the preexisting flaw and its quantity on the strength, deformability, and fracture behaviors were studied.

This paper is organized as follows. Experimental preparation and procedure is illustrated in Section 2. Mechanical properties of rock specimens are investigated in Section 3. The cracking mechanism and acoustic emission feature are discussed in Section 4, and the conclusions are finally drawn in Section 5.

\section{Experimental Preparation and Procedure}

2.1. Experimental Preparation. In this paper, the experimental material is sandstone that exhibits homogeneous texture, nonweathering phenomenon, and good integrality and derived from Chongqing city, China. In order to reduce the effect of the end friction on the experimental results, the length-diameter ratio of the sandstone specimen should be in the range of 2.0-3.0. Therefore, the standard cylinder specimen is adopted in the experiment and the size of the sandstone specimen is $100 \mathrm{~mm}$ long and $50 \mathrm{~mm}$ in diameter. The preexisting fissures in sandstone samples are fabricated with high-pressure water-jet cutting device, and the intact and flaw-contained sandstone specimens are exhibited in Figure 1. Geometric dimensions of the flaw-contained rock specimens is described as below: the width of the preexisting flaws is $1 \mathrm{~mm}$; $\alpha$ indicate the angle of prefabricated crack and it is fixed to $45^{\circ}$; and $2 a$ and $2 b$ indicate the prefabricated 


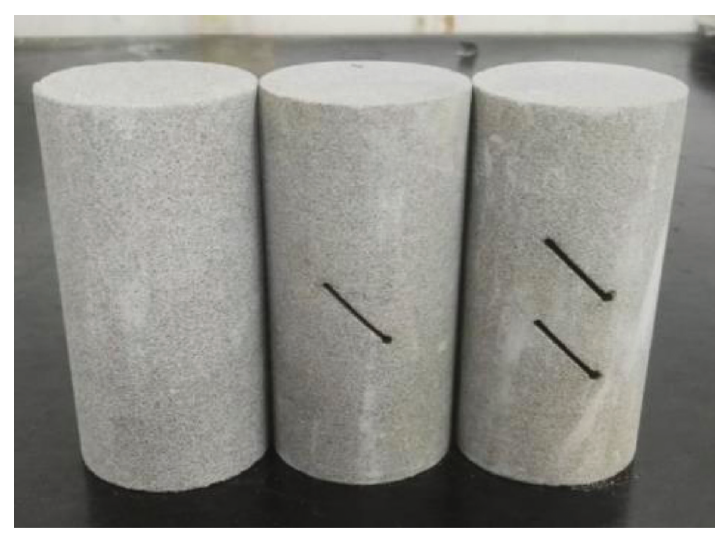

(a)

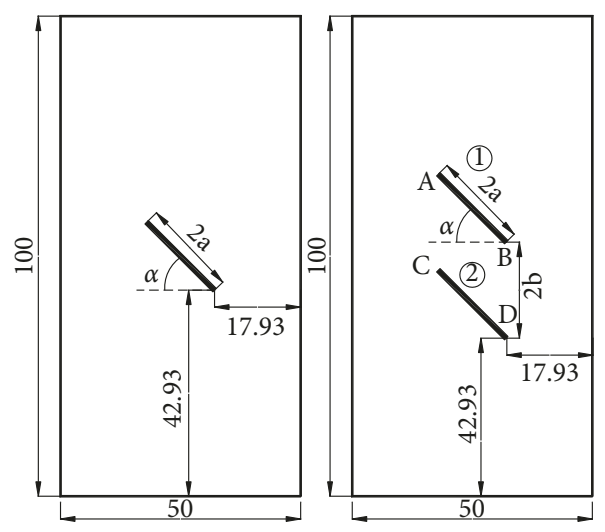

(b)

Figure 1: The intact and flaw-contained sandstone specimens (unit: mm).

crack length and ligament length which are, respectively, fixed to $20 \mathrm{~mm}$ and $20 \mathrm{~mm}$. The number of preexisting cracks is fabricated to varying from 0 to 2 in order to investigate the effects of the preexisting flaw and its number on the strength, deformability, fracture behaviors, and the resulting $\mathrm{AE}$ evolution characteristics of sandstone specimens under uniaxial compression. The intact, single, and double-flawed sandstone specimens are experimented three times to ensure the accuracy of the results. The geometry parameter of the intact and flaw-contained sandstone specimens is shown in Table 1.

2.2. Experimental Procedure. In compression tests, an MTS815 rock mechanics servo-controlled testing system is used to test the intact and flaw-contained rock specimens. Vertical load is applied to the upper surface of the sandstone samples until ultimate failure occurs. All the experiments are carried out by the displacement-load system, and the loading rate is $1.67 \times 10^{-6} \mathrm{~s}^{-1}(0.1 \mathrm{~mm} / \mathrm{min})$ that can guarantee the rock samples in a quasi-static equilibrium during the loading process. The data acquisition system can simultaneously and continuously collect data of loads and deformations during the uniaxial compression experiment. All the intact and flaw-contained specimens are experimented under natural and dry conditions so as to obtain the accurate results as well as the best comparison.

In order to explore the crack initiation, growth, and coalescence characteristics of the intact and flaw-contained sandstone specimens during the deformation process, the acoustic emission (AE) technique is applied in this experiment. The 12CHS PCI-2 acoustic emission instrument is used to record the $\mathrm{AE}$ events, and the frequency of $\mathrm{AE}$ equipment varies from $1 \mathrm{kHz}$ to $3 \mathrm{MHz}$. At the same time, the photographic monitoring technique is employed to capture images when the flaws initiate, grow, coalesce, and ultimately fail. Two AE sensors are mounted on the broadside face of the test specimen using grease as a coupling agent and then are fixed slightly by using a cellulose tape. The equipment used in the experiment is given in Figure 2.

\section{Mechanical Properties of Rock Specimens}

In order to explore the mechanical properties of rock specimens under the uniaxial compression, the features and differences of strain-stress curves of intact and flawcontained sandstone specimens are discussed. The strength and deformation parameters of the tested sandstone specimens are also discussed, including the effect of the amount of fissures on the uniaxial compression strength, elastic modulus, and peak strain.

3.1. Stress-Strain Behavior. The axial stress-strain curves (labeled in black) of intact and flaw-contained sandstone specimens are depicted in Figures 3-5 and the radial stressstrain curves (labeled in red). The tested sandstone specimens exhibit significant brittle behavior, namely, a large stress jump is observed in all axial stress-strain curves. Moreover, all axial stress-strain curves undergo initial compaction, linear elastic deformation, nonlinear deformation, and brittle failure stage. It can be observed that no significant stress jump occurred at prepeak and postpeak for intact sandstone specimens, as shown in Figure 3. The stress-strain curves of flaw-contained sandstone specimens, however, exhibited distinct stress jump during the entire loading process. This is a radical difference existing between the intact and flaw-contained specimens. Such experimental observations are similar to those reported by Lee and Jeon [41]. This phenomenon of stress jump can be explained by the principle of energy dissipation in rock. The elastic strain energy of crack tip will be released suddenly when the elastic strain energy accumulated and exceeded the critical strain energy of crack tip during the deformation of flawed rock sample, which leads to the sudden decrease of stress-strain curves (stress jump) within the process of elastic deformation.

The number of preexisting flaws has a strong influence on the stress-strain responses of flawed sandstone specimens, especially around the peak loads. For sandstone specimens containing one single preexisting flaw, the stress jump occurs at the postpeak stage (Figure 4), while for sandstone specimens containing double preexisting flaws, 
TABLE 1: Geometry parameter of the intact and flaw-contained specimens.

\begin{tabular}{|c|c|c|c|c|c|c|}
\hline Specimen & $H(\mathrm{~mm})$ & $W(\mathrm{~mm})$ & $\alpha\left({ }^{\circ}\right)$ & $2 a(\mathrm{~mm})$ & Fissure width $(\mathrm{mm})$ & $2 b(\mathrm{~mm})$ \\
\hline \multicolumn{7}{|c|}{ Intact specimen } \\
\hline A1 & 100.05 & 50.02 & - & - & 0 & - \\
\hline A2 & 100.01 & 50.06 & - & - & 0 & - \\
\hline A3 & 100.10 & 50.11 & - & - & 0 & - \\
\hline \multicolumn{7}{|c|}{ Single-flawed specimen } \\
\hline B1 & 100.06 & 50.13 & 45 & 20 & 1 & - \\
\hline $\mathrm{B} 2$ & 100.03 & 49.96 & 45 & 20 & 1 & - \\
\hline B3 & 100.08 & 50.05 & 45 & 20 & 1 & - \\
\hline \multicolumn{7}{|c|}{ Double-flawed specimen } \\
\hline $\mathrm{C} 1$ & 100.02 & 50.07 & 45 & 20 & 1 & 20 \\
\hline $\mathrm{C} 2$ & 100.12 & 49.98 & 45 & 20 & 1 & 20 \\
\hline $\mathrm{C} 3$ & 100.04 & 50.01 & 45 & 20 & 1 & 20 \\
\hline
\end{tabular}

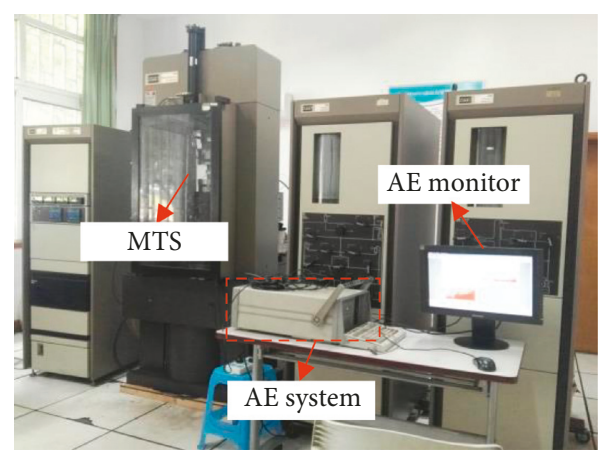

(a)

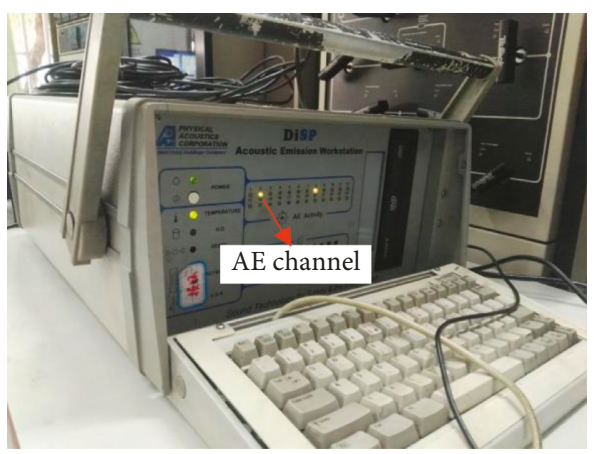

(b)

FIGURE 2: The experimental equipment. (a) MTS815 equipment. (b) 12CHS PCI-2 AE system.

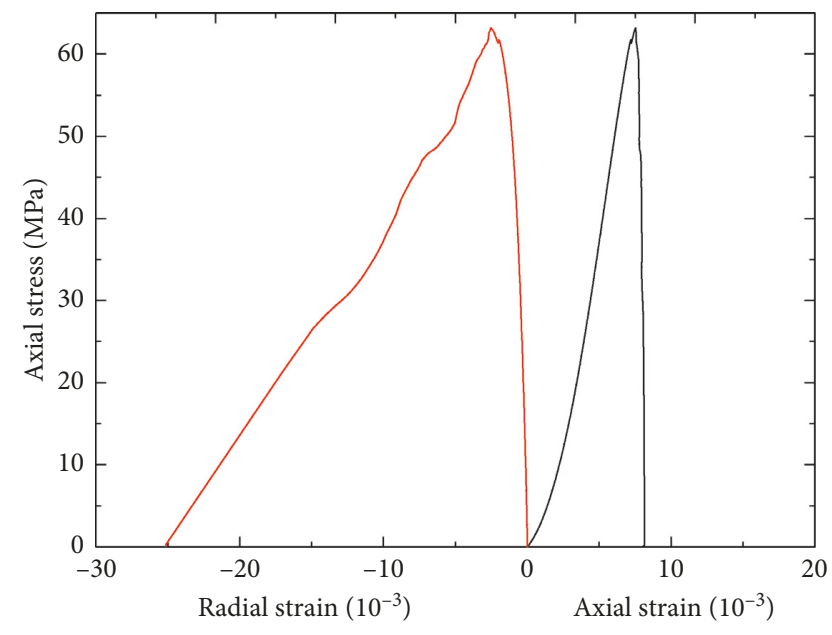

FIgURE 3: Typical stress-strain curve of an intact specimen.

the stress jump occurs at the prepeak stage (Figure 5). Moreover, the stress jump degrees at the postpeak for singleflawed sandstone specimens are obviously larger than those at the prepeak for double-flawed sandstone specimens. This phenomenon is mainly caused by the distribution characteristics of precrack and the failure modes of flawed rock specimens. The mechanism interpreting the stress jump at the postpeak for specimens containing one single preexisting flaw is that the new initiated cracks successively grow and

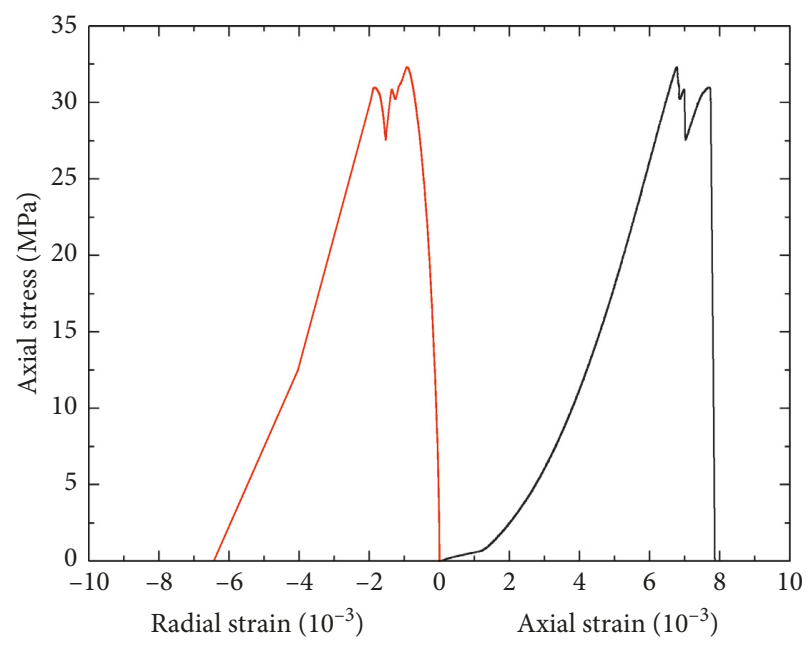

FIgURE 4: Typical stress-strain curve of a single-flawed specimen.

eventually travel through the vertical direction of specimens when the compression loads reach the peak stress, and then the penetrated cracks break the specimen into two or more separate supporting structures (Figure 6). That is to say, the compression loads that are originally carried by the specimen are correspondingly transferred to these separate supporting structures at the postpeak. When the remaining supporting structures fail, the final stress jump is found, which indicates the eventual failure of sandstone specimens. 


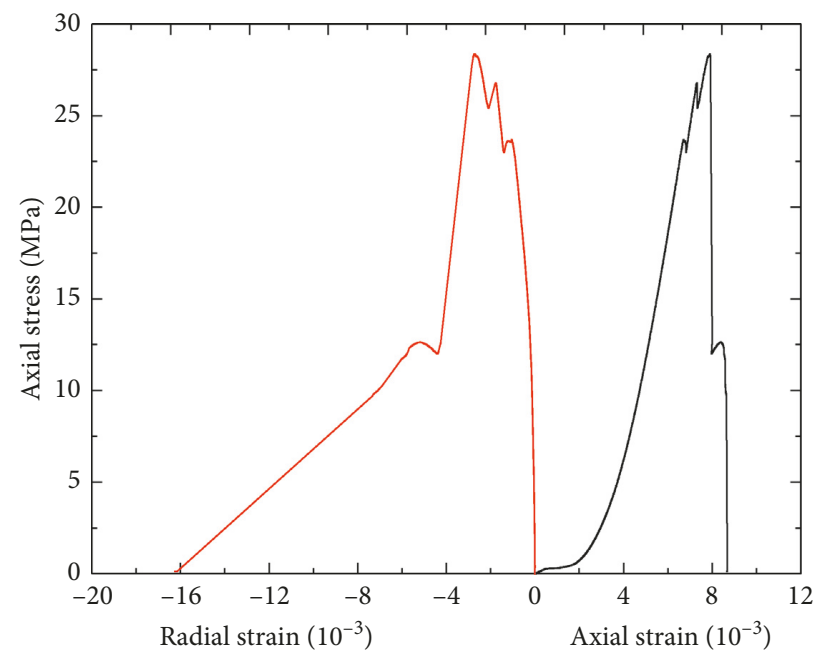

Figure 5: Typical stress-strain curve of a double-flawed specimen.

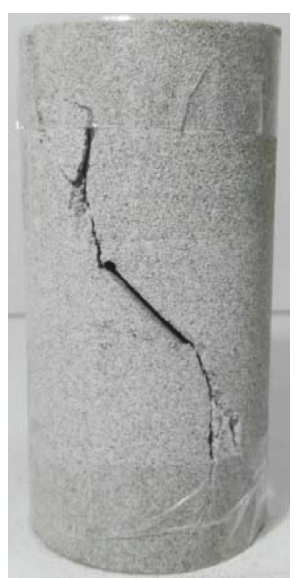

(a)

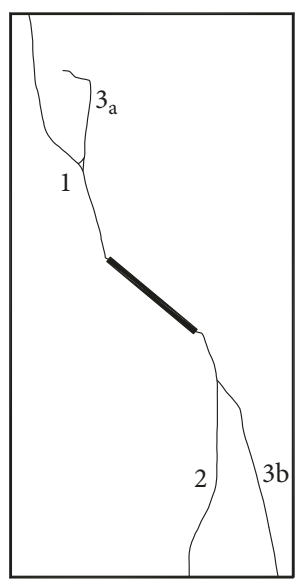

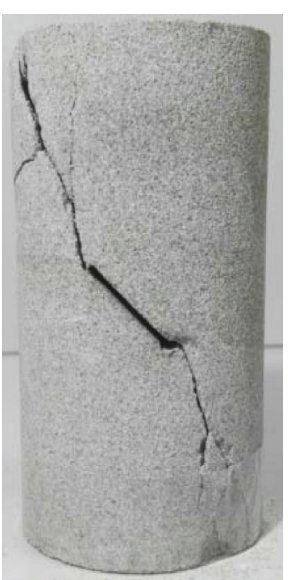

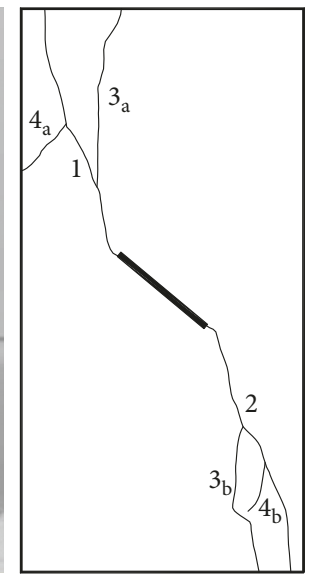

(b)

FIGURE 6: Eventual failure of specimens containing single preexisting flaw under uniaxial compression. (a) B1 specimen. (b) B2 specimen.

The mechanism of the stress jump at the prepeak for specimens containing double preexisting flaws is rather complex. As observed in this experimental study on specimens containing double preexisting flaws, the stress jump at the prepeak is mainly caused by the crack initiation and crack coalescence within the bridge zone. However, the fracturing behavior within the bridge zone cannot trigger the whole failure of sandstone specimens. The sandstone specimens can continue to support the increasing compression loads until it reaches the uniaxial compression strength of rock material. When the compression load amounts to the peak stress, the cracking behaviors without the bridge zone induce the unstable failure of sandstone specimens. For specimens containing double preexisting flaws, the formed fragments cannot bear the vertical compression loads. Therefore, the formation of fragments suggests the eventual failure of sandstone specimens. The number of preexisting flaw affects the initial compaction to some extent. Figures 3-5 show that the initial compaction increases stage with increasing the number of preexisting flaw. The initial compaction stage is mainly caused by the closure of microcracks and microvoids under uniaxial compression. The preexisting cracks lead to the increase of the porosity of the rock sample, which results in the increase of the initial compaction stage with the increasing the number of preexisting flaw.

3.2. Strength and Deformation Properties. Figure 7 shows the axial stress-strain curves of intact and flaw-contained sandstone specimens under uniaxial compression. From Figure 7, the strength and deformation parameters of tested sandstone specimens, including uniaxial compression strength $\sigma_{\mathrm{c}}$, peak strain $\varepsilon_{\mathcal{c}}$, and elastic modulus $E_{\mathrm{s}}$, can easily be obtained. The effects of preexisting flaw and its number on the strength and deformation parameters of sandstone specimens under uniaxial compression are shown in Figure 8.

Figure 8(a) shows the uniaxial compression strength $\sigma_{\mathrm{c}}$ of sandstone specimens versus the fissure number. As illustrated in Figure 8(a), the uniaxial compression strength 


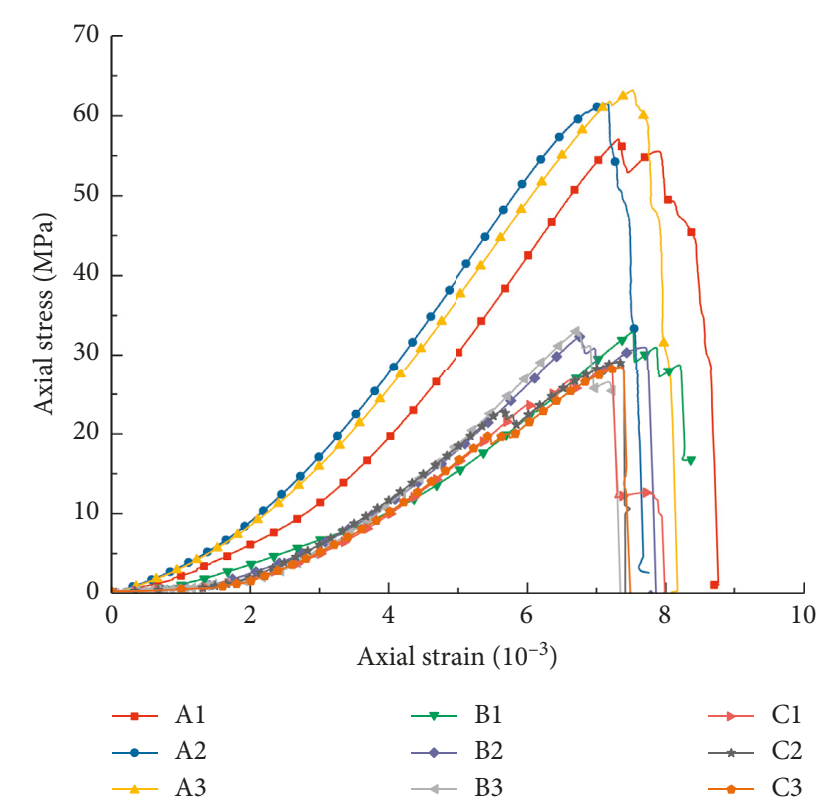

Figure 7: Axial stress-strain curves of the tested sandstone specimens under uniaxial compression.

decreases with increasing fissure number. The average uniaxial compression strength $\sigma_{\mathrm{c}}$ decreases from $60.57 \mathrm{MPa}$ to $32.76 \mathrm{MPa}$ as the fissure number increases from 0 to 1 , and the uniaxial compression strength decreases by $45.91 \%$. When the fissure number increases from 1 to 2 , the average uniaxial compression strength $\sigma_{\mathrm{c}}$ decreases from $32.76 \mathrm{MPa}$ to $28.62 \mathrm{MPa}$, and the uniaxial compression strength decreases by $12.64 \%$.

Figure 8(b) suggests the role of the fissure number on the peak strain $\varepsilon_{\mathrm{c}}$ of sandstone specimens under uniaxial compression. The average peak strain approximately linearly decreases with increasing fissure number. The average peak strain of intact specimens is approximately $8.24 \times 10^{-3}$. When the fissure number increases from 1 to 2 , the average peak strain decreases from $7.89 \times 10^{-3}$ to $7.61 \times 10^{-3}$, which, respectively, decreases by $4.25 \%$ and $3.55 \%$.

Figure 8(c) shows the sensibility of the elastic modulus of sandstone specimens under uniaxial compression to the fissure number. The trend of the elastic modulus depicted in Figure $8(\mathrm{c})$ is in good agreement with that of uniaxial compression strength. When the fissure number increases from 0 to 2 with an interval of 1 , the average elastic modulus decreases from $12.01 \mathrm{GPa}$ to $7.75 \mathrm{GPa}$ and $6.41 \mathrm{GPa}$, which decreases by $35.47 \%$ and $17.29 \%$, respectively. It was found that the strength parameters of the rock specimen are obviously weakened by the preexisting fissures, so the uniaxial compression strength, elastic modulus, and peak strain of rock specimens gradually decrease with the increase of the number of joints.

\section{Cracking Mechanism and Acoustic Emission Feature}

The characteristics of crack propagation and acoustic emission are of great significance for profound understanding of failure process of rocks and contribution to the evaluation the stability and safety of rock mass engineering [42]. To reveal the failure mechanism of the rock under uniaxial compression, the cracking processes and acoustic emission characteristics of intact and flawcontained sandstone specimens are discussed.

4.1. Cracking Process. The cracking processes of intact and flaw-contained sandstone specimens under uniaxial compression are obviously different as well as the failure modes in this experimental study. Figure 9 shows the ultimate failure patterns of intact sandstone specimens, and Figures 6 and 10 show the ultimate failure patterns of single- and double-flawed sandstone specimens, respectively. The number in the figures indicates the cracking order observable by photographic monitoring, and the following subscript letters indicate that these cracks simultaneously emanate from different positions.

For the intact sandstone specimens, the eventual failure mode exhibits the splitting failure. In specimen A1, one tensile crack (crack $1_{a}$ ) initiates from top boundary of the specimen and propagates towards the bottom boundary of the specimen, while another tensile crack ( $\mathrm{crack} 1_{\mathrm{b}}$ ) evolves from left top boundary of the specimen towards the bottom boundary of the specimen. Subsequently, crack 2 initiates from the middle of the specimen and extends towards the bottom boundary of the specimen and then coalesces with crack $1_{\mathrm{a}}$. Finally, crack $3_{\mathrm{a}}$ and crack $3_{\mathrm{b}}$ occur simultaneously, as shown in Figure 9(a). In specimen A2, one tensile crack (crack 1) initiates from top boundary of the specimen and grows towards the bottom boundary of the specimen, and another tensile crack (crack 2) travels from the middle of the specimen to the top boundary of the specimen. Crack 3 a emanates from the middle of the specimen and spreads towards the bottom boundary of the specimen, and at the same time, crack $3_{\mathrm{b}}$ initiates from bottom boundary of the specimen and connects with crack 1 . This indicates the splitting failure of intact sandstone specimens.

In specimen B1, one shear crack (crack 1) initiates from the upper tip of preexisting flaw and grows towards the top boundary of the specimen. After that, another shear crack (crack 2) is observed emanating from the lower tip of fissure and propagates in the downward direction. Finally, one tensile crack (crack $3 \mathrm{a}$ ) and one shear crack (crack 3 b) are observed from crack 1 and 2 towards the opposite direction, as shown in Figure 6(a). The cracking modes of specimens B1 and B2 show very similar results. In specimen B2, two shear cracks (cracks 1 and 2) are observed, respectively, from the upper and lower tips of preexisting flaw. Tensile cracks 3 a and $3_{\mathrm{b}}$ initiate in specimen $\mathrm{B} 2$ when cracks 1 and 2 grow to a certain distance. Tensile cracks $3_{\mathrm{a}}$ and $3_{\mathrm{b}}$ gradually extend towards the top and bottom boundaries of specimens. Finally, cracks $4_{\mathrm{a}}$ and $4_{\mathrm{b}}$ were formatted simultaneously as shown in Figure 6(b).

In specimen $\mathrm{C} 1$, one tensile wing crack (crack 1 ) initiates from tip C of flaw (1) and grows towards the top boundary of the specimen, and then two tensile wing cracks ( crack $2_{\mathrm{a}}$ and $2 \mathrm{~b}$ ) were observed from tips $\mathrm{A}$ and $\mathrm{B}$ of flaw (1) and then 


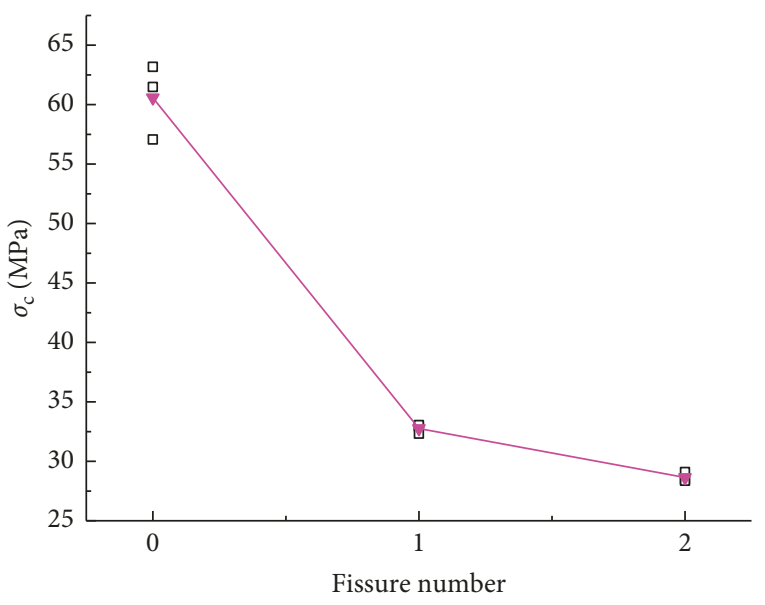

口 Experimental value $\rightarrow$ Average value

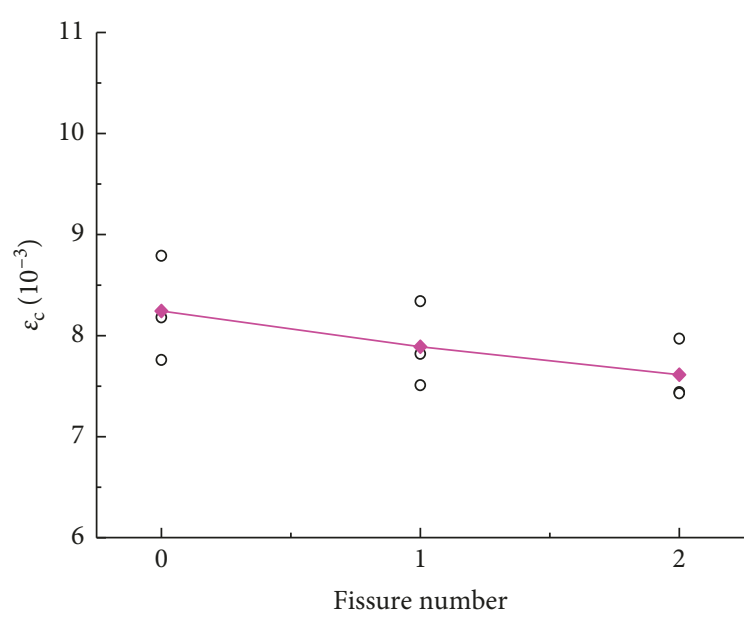

- Experimental value

$\rightarrow$ Average value

(a)

(b)

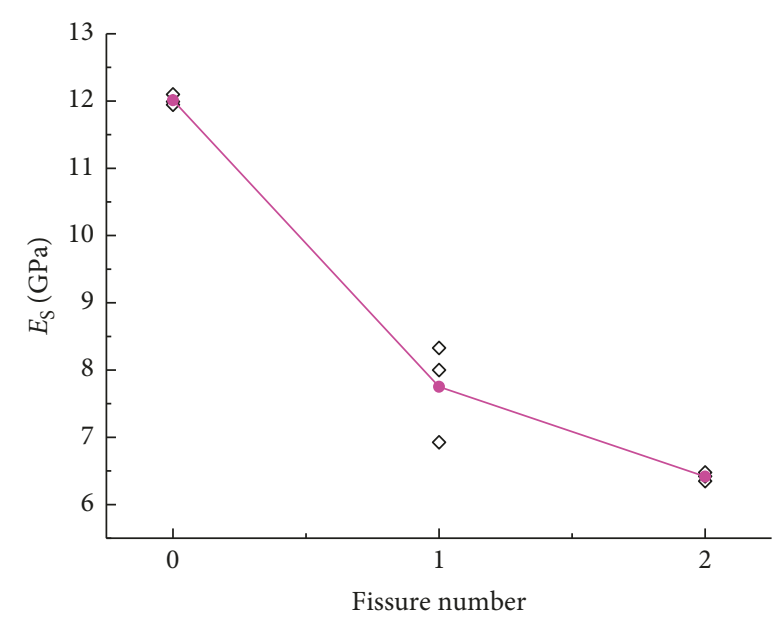

$\diamond$ Experimental value

$\checkmark$ Average value

(c)

FIGURE 8: Strength and deformation parameters of the sandstone specimens versus fissure number. (a) Uniaxial compression strength. (b) Peak strain. (c) Elastic modulus.

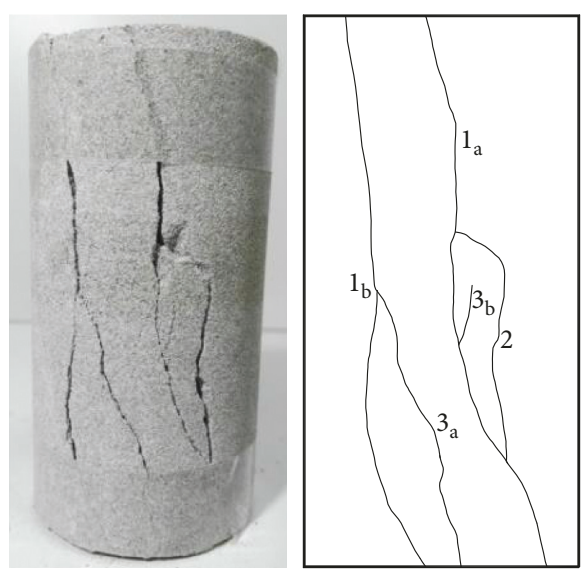

(a)
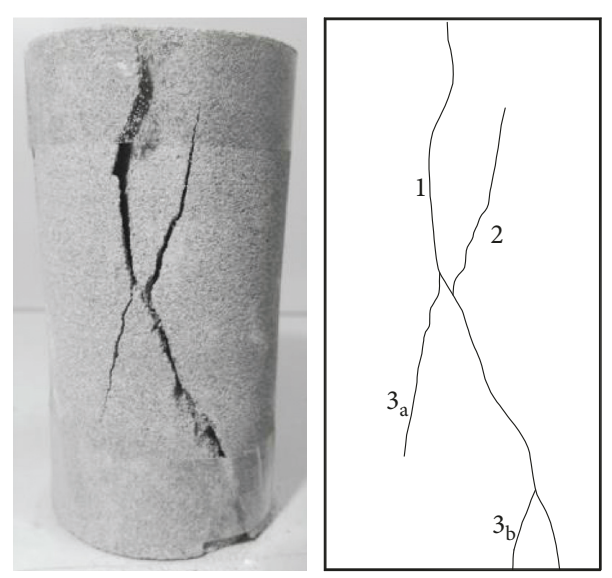

(b)

Figure 9: Eventual failure of intact specimens under uniaxial compression. (a) A1 specimen. (b) A2 specimen. 


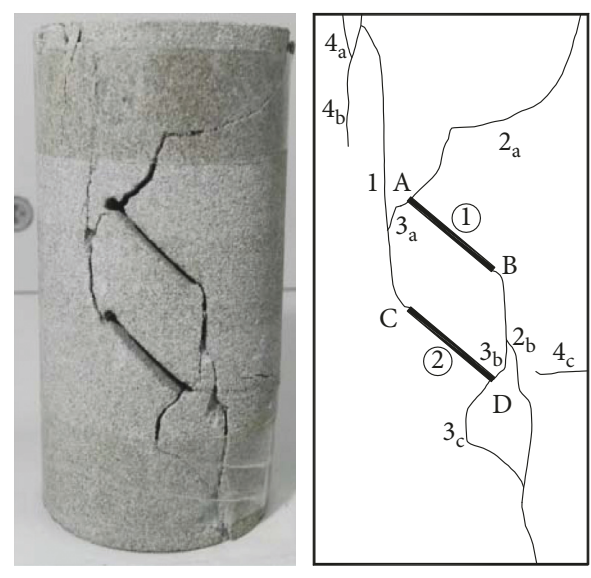

(a)

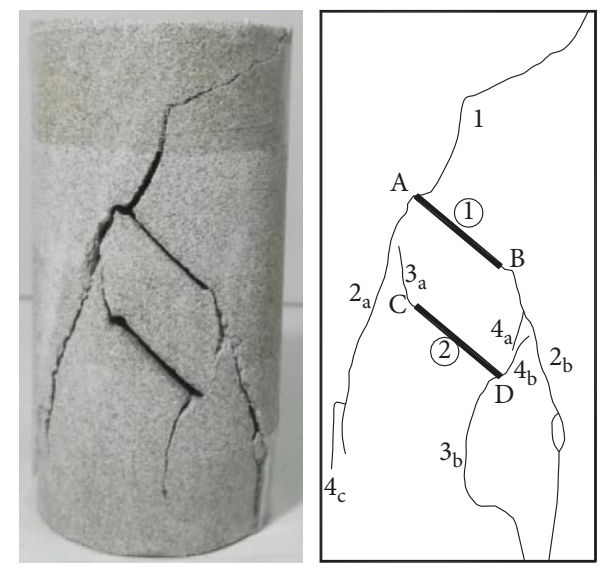

(b)

FIgURE 10: Eventual failure of specimens containing double preexisting flaws under uniaxial compression. (a) C1 specimen. (b) C2 specimen.

extended to the opposite direction. Subsequently, two antiwing cracks (crack $3_{\mathrm{a}}$ and $3_{\mathrm{b}}$ ) emanate from tip A of fissure (1) and tip D of fissure (2), respectively. The tensile crack 3 a propagates towards the bottom boundary of the sandstone specimen and coalesces with the tensile wing crack 1 , and the tensile crack $3_{\mathrm{b}}$ extends towards the top boundary of the specimen and coalesces with the tensile crack 2. Simultaneously, another tensile crack (crack 3 c) initiates from tip D of fissure (2) towards bottom boundary of the specimen and also coalesces with the tensile crack 2. Finally, far-field cracks $4_{\mathrm{a}}, 4_{\mathrm{b}}$, and $4_{\mathrm{c}}$ appear at left top of the specimen or at middle region of the specimen, as shown in Figure 10(a). The propagating paths of tensile crack are tortuous, which is also due to the fact that the crack always propagates along the boundaries of large quartz grains within the matrix of sandstone [37].

Compared with the experimental observations from specimen C1, the cracking mode in specimen C2 are clearly similar. In specimen $\mathrm{C} 2$, one tensile wing crack (crack 1) initiates from tip A of flaw (1) and grows towards the top boundary of the specimen. One antiwing crack $2_{\mathrm{a}}$ and one tensile crack $2_{\mathrm{b}}$ emanate from tips A and B of flaw (1), respectively, and extend towards the bottom boundary of the specimen. Subsequently, two tensile cracks (cracks $3_{\mathrm{a}}$ and $3_{\mathrm{b}}$ ) initiate from tips C and D of flaw (2). Afterwards, tensile cracks $3_{\mathrm{a}}$ and $3_{\mathrm{b}}$ spread towards the top and bottom boundaries of the specimen, respectively. Subsequently, one antiwing crack (crack $4_{b}$ ) emanates from tip D of flaw (2) and then grows towards the top boundary of the specimen and ultimately coalesces with crack $2_{\mathrm{b}}$. At the same time, cracks $4_{\mathrm{a}}$ and $4_{\mathrm{c}}$ are formatted simultaneously, as shown in Figure 10(b). There exist two coalesced cracks within the bridge zone. More specifically, the crack emanating from tip A of flaw (1) links with the crack initiating from tip C of flaw (2), and the crack emanating from tip B of flaw (1) coalesces with the crack initiating from tip D of flaw (2).

In a word, the failure mode for intact sandstone specimens exhibits the splitting failure, whereas for flawcontained sandstone specimens, it exhibits the mixed failure modes of shear and tension. With regard to the effects of the preexisting flaws, it can be concluded that the cracking behaviors for specimens containing double preexisting flaws are more complex than those for specimens containing single preexisting flaws. In terms of the postpeak behavior, the brittle characteristics of jointed rock samples are more obvious than that of intact rock samples. The main reason for this phenomenon is that a relative significant fragmentation occurs (the crack coalescence can be observed within the specimens containing double preexisting flaws) when the fractured rock mass is destroyed under the compression process (Figure 10), which leads to the decrease of the bearing capacity of the supporting structures because of the complete failure of the fractured rock sample. Therefore, the brittleness is obvious for specimens containing preexisting fissure in the postpeak stage.

4.2. Acoustic Emission Evolution. In this paper, AE technique is applied to explore real-time cracking behaviors of intact and flaw-contained sandstone specimens, including the crack initiation, growth, and coalescence.

Figure 11 shows the axial stress of the tested sandstone specimens versus time and $\mathrm{AE}$ counts. It is found from Figure 11 that very few AE counts is recorded when the stress state remains at initial compression stage and the elastic deformation stage. As compression loads increase, the cracking behaviors are gradually triggered. Figures 11(a) and 12(a) shows that $\mathrm{AE}$ events became active when the stress level of sandstone specimens reaches the uniaxial compression strength. This is because the cracking behaviors are dramatically triggered at this moment. At the postpeak, the $\mathrm{AE}$ events remain active, which is due to the sustainable damage of supporting structure.

The $\mathrm{AE}$ counts and $\mathrm{AE}$ energy of sandstone specimens containing single preexisting flaw are shown in Figures 11(b) and $12(\mathrm{~b})$, respectively. The crack initiation and propagation processes are observed after the uniaxial compression strength, which leads to the difference in AE counts. Crack 1 (Figure 6(a)) initiates and propagates when the stress level of 


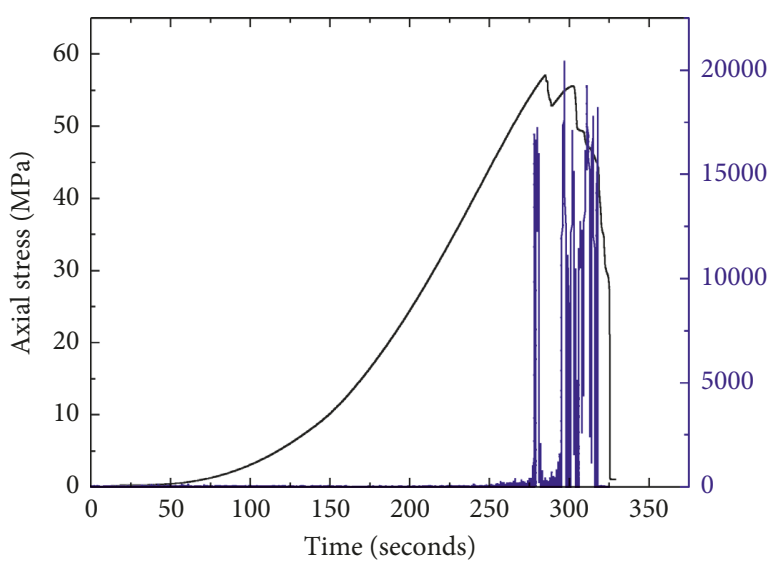

(a)

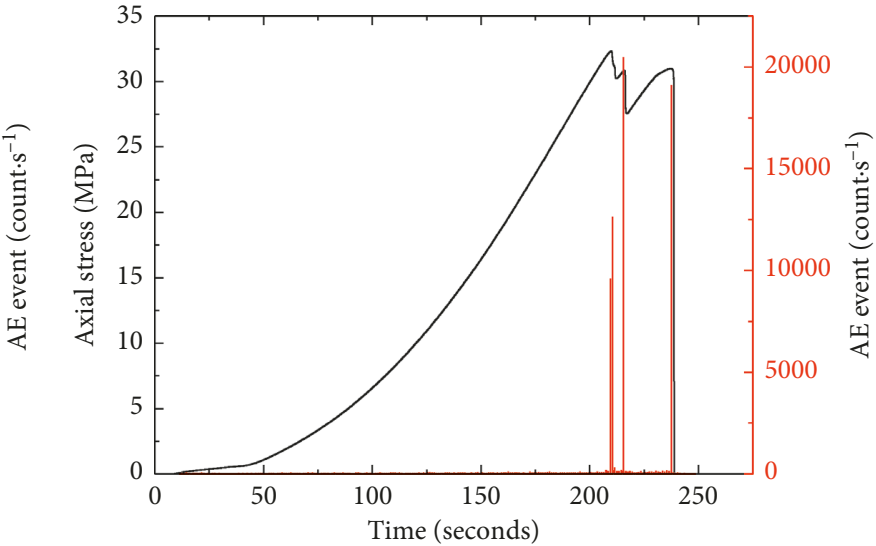

(b)

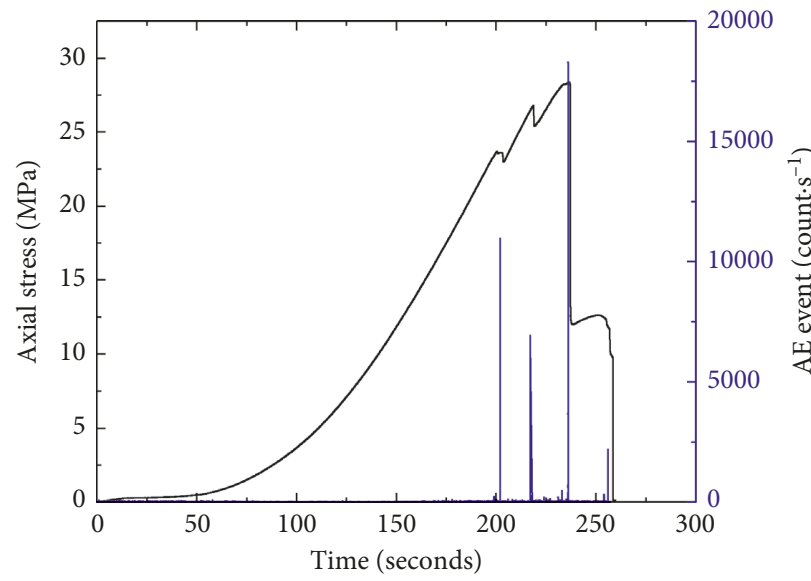

(c)

FIgURE 11: AE counts of sandstone specimens containing different fissures: (a) intact specimen, (b) one fissure, and (c) two fissures.

sandstone specimens reach the uniaxial compression strength, which produces a big $\mathrm{AE}$ event and a sudden increase in the AE counts and AE energy. With the increase of deformation, the axial stress further decreased, which can be attributed to the initiation crack 2 (Figure 6(a)). Compared with crack 1 , the AE count and AE energy induced by crack 2 is more active. This is because crack 2 extended a long distance, which makes the specimen split into several separated supporting structures, and more elastic strain energy is released at this stage. Therefore, the AE count and AE energy induced by crack 2 is more active at this stage. Then the axial stress again increased with the increase of deformation, and the initiation of crack 3 (Figure 6(a)) also triggers large $\mathrm{AE}$ counts and $\mathrm{AE}$ energy. Compared with the intact sandstone specimen, it is found that AE events significantly decrease after the uniaxial compression strength. The main reason lies in the preexisting flaws that lead to the significant weakening of energy reserve of the rock specimen. The progressive cracking behavior of the preexisting flaws releases the elastic strain energy accumulated by the compression loads. When the elastic strain energy is dissipated by the progressive cracking behavior, both AE counts and $\mathrm{AE}$ energy reduce to some extent.
The crack initiation and propagation processes are observed at the prepeak. As illustrated in Figures 11(c) and 12(c), the stress that drops in the stress-time curves in Figures 11(b) and 12(b) all corresponds to the progressive cracking behavior within sandstone specimens. Herein the progressive cracking behavior includes the crack initiation, growth, and coalescence. These cracking behaviors were accompanied by a big AE event and a sudden increase in the AE counts and AE energy. Tensile crack 1 (Figure 10(a)) initiates from the tip $\mathrm{C}$ of flaw (1) when the axial stress increases to $23.01 \mathrm{MPa}$, which corresponds to the first big $\mathrm{AE}$ counts. When the stress is loaded to $26.79 \mathrm{MPa}$, tensile cracks (Figure 10(a)) $2_{\mathrm{a}}$ and 2 b initiate simultaneously, which leads to a great stress jump in the stress-strain curve and a sudden increase in the AE counts and AE energy. After that, two antiwing cracks $3_{\mathrm{a}}$ and $3_{\mathrm{b}}$ and one tensile crack $3_{\mathrm{c}}$ (Figure 10(a)) emanate simultaneously, which leads to an obvious stress jump from $28.33 \mathrm{MPa}$ to $12.58 \mathrm{MPa}$. At this moment, largest AE counts can be observed. Herein the largest $\mathrm{AE}$ counts are attributed to the initiation of cracks $3_{\mathrm{a}}$, $3_{\mathrm{b}}$, and $3_{\mathrm{c}}$. When the stress is increased from $12.09 \mathrm{MPa}$ to 12.63 $\mathrm{MPa}$, far-field cracks $4_{\mathrm{a}}, 4_{\mathrm{b}}$, and $4_{\mathrm{c}}$ (Figure $10(\mathrm{a})$ ) occur, and larger $\mathrm{AE}$ count is found along with a large $\mathrm{AE}$ 


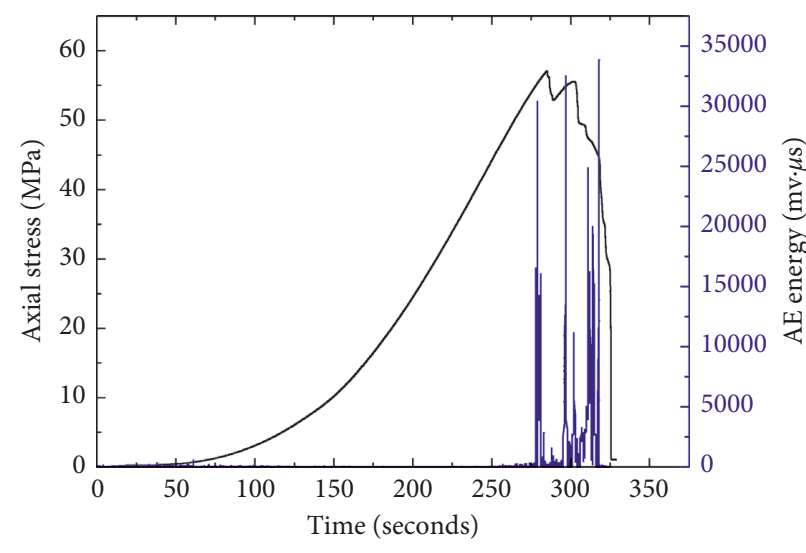

(a)

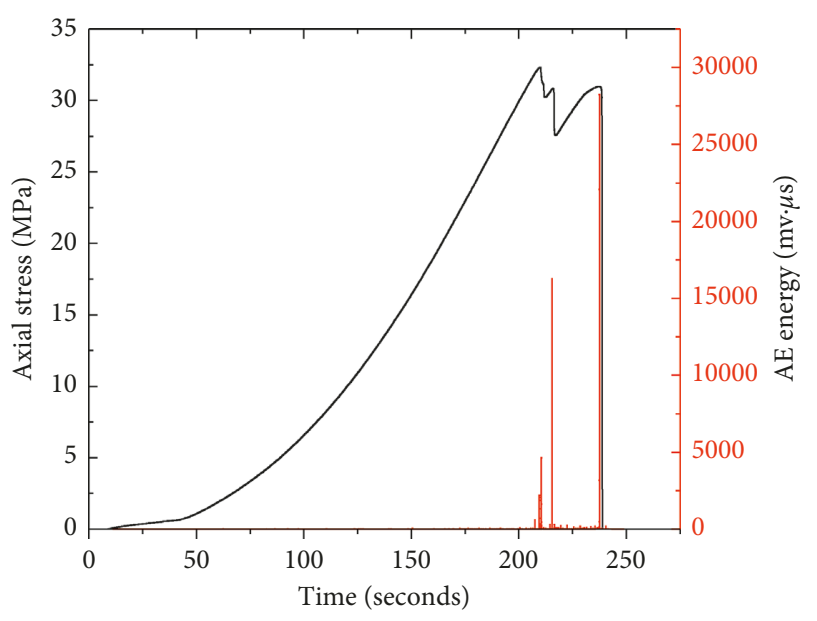

(b)

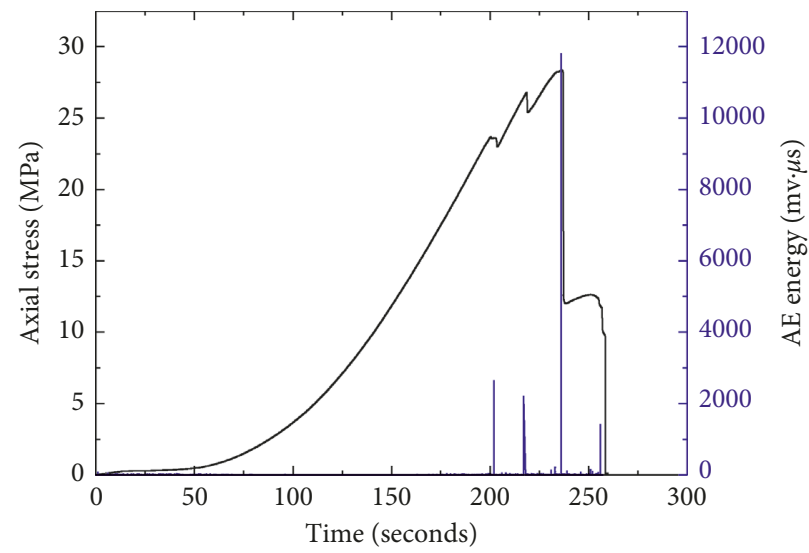

(c)

Figure 12: AE energy of sandstone specimens containing different fissures: (a) intact specimen, (b) one fissure, and (c) two fissures.

energy. Compared with sandstone specimens containing single preexisting flaw, the $\mathrm{AE}$ events for specimens containing double preexisting flaws also decrease. This is because more fragments are generated for double-flawed specimens, and more elastic strain energy is released during the loading process. Both $\mathrm{AE}$ counts and $\mathrm{AE}$ energy reduce to a larger extent.

Figure 13 shows the maximum $\mathrm{AE}$ counts and $\mathrm{AE}$ energy versus the number of preexisting flaws. It is found from Figure 13 that the maximum $\mathrm{AE}$ counts and $\mathrm{AE}$ energy all decrease with increasing number of preexisting flaw, and the reduction of the maximum $\mathrm{AE}$ events increases. When the number of preexisting flaws increases from 0 to 1 , the maximum $\mathrm{AE}$ counts decrease from $21852 \mathrm{mv} \cdot \mu \mathrm{s}$ to $20449 \mathrm{mv} \cdot \mu \mathrm{s}$, which decreases by $6.42 \%$. However, the maximum AE counts decrease from $20449 \mathrm{mv} \cdot \mu$ s to $18290 \mathrm{mv} \cdot \mu$ s (by $10.56 \%$ ), as the number of preexisting flaw increases from 1 to 2 . In terms of $\mathrm{AE}$ energy, the maximum $\mathrm{AE}$ energy decreases from $33864 \mathrm{mv} \cdot \mu \mathrm{s}$ to $28239 \mathrm{mv} \cdot \mu \mathrm{s}$ and $11795 \mathrm{mv} \cdot \mu \mathrm{s}$ when the number of preexisting flaw increases from 0 to 2 with an interval of 1 . And the maximum AE energy decreased by $16.56 \%$ and $58.23 \%$, respectively. The energy reserve of the rock specimen is significantly weakened by the number of

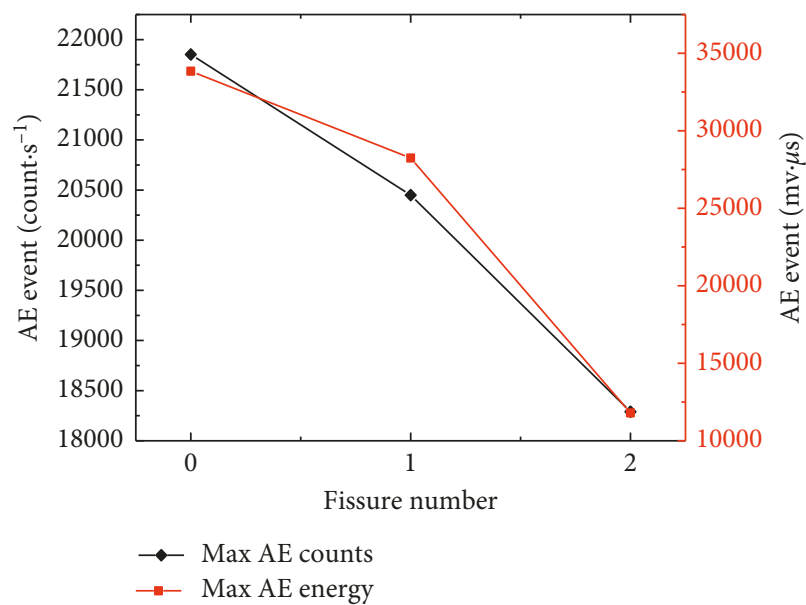

Figure 13: The influence of the fissure number on maximum AE counts and energy of sandstone specimens.

preexisting flaws, which lead to the decrease of elastic strain energy in the rock sample. The release of elastic strain energy decreases with the increasing amount of preexisting fissure when the crack propagation and ultimate failure of rock samples occur during the load process. Therefore, the 
maximum AE counts and AE energy all decrease with increasing number of preexisting flaws.

\section{Conclusions}

This study explored and discussed the mechanical properties of the intact and flaw-contained rock subjected to axial compression load by the experimental study. In addition, the photographic and emission monitoring technique were introduced to analyze the crack propagation and acoustic emission characteristics of the sandstone specimen. Based on the experimental results, the main conclusions can be drawn as follows:

(1) The stress-strain curves show that no significant stress jump exhibited at the prepeak and postpeak points for intact sandstone specimens, the flawcontained sandstone specimens exhibited distinct stress jump during the entire loading process. For sandstone specimens containing single preexisting flaw, the stress jump occurred at the postpeak, while the stress jump occurred at the prepeak for sandstone specimens containing double preexisting flaws.

(2) The strength parameters of the rock specimen are obviously weakened by the preexisting fissures. The initial compaction stage of the rock specimen increases with the increasing amount of preexisting flaw; meanwhile, the uniaxial compression strength of rock specimens generally decreases with the increasing number of preexisting fissure and the peak strain and the elastic modulus.

(3) The failure modes of intact and flaw-contained sandstone specimens exhibit the splitting failure and the mixed failure modes of shear and tension, respectively. The cracking behaviors for specimens containing double preexisting flaws are more complex than those for the specimens containing single preexisting flaws.

(4) The amount of released elastic strain energy decreases with increasing preexisting fissure number when the crack propagation and ultimate failure of the rock samples occur during the loading process, which results in the decrease of the maximum $\mathrm{AE}$ counts and AE energy with increasing number of preexisting flaw.

\section{Data Availability}

The data used to support the findings of this study are available from the corresponding author upon request.

\section{Conflicts of Interest}

The authors declare that they have no conflicts of interest.

\section{Acknowledgments}

This research was supported by the National Natural Science Foundation of China (nos. 51325903 and 51679017), Project
973 (Grant no. 2014CB046903), and Natural Science Foundation Project of CQ CSTC (CSTC nos.: cstc2015jcyjys30001, cstc2016jcyjys0005, and cstc2015jcyjys30006).

\section{References}

[1] P. H. S. W. Kulatilake, B. Malama, and J. Wang, "Physical and particle flow modeling of jointed rock block behavior under uniaxial loading," International Journal of Rock Mechanics and Mining Sciences, vol. 38, no. 5, pp. 641-657, 2001.

[2] X. Yang, P. H. S. W. Kulatilake, H. Jing, and S. Yang, "Numerical simulation of a jointed rock block mechanical behavior adjacent to an underground excavation and comparison with physical model test results," Tunnelling and Underground Space Technology, vol. 50, pp. 129-142, 2015.

[3] Q. Zhang, D. Ma, J. Liu, K. Zhang, and Z. Fan, "Numerical studies on the failure process of heterogeneous rock material with preexisting fracture under uniaxial compression," Advances in Civil Engineering, vol. 2018, Article ID 9203549, 12 pages, 2018.

[4] X. Fan, R. Chen, H. Lin, H. Lai, C. Zhang, and Q. Zhao, "Cracking and failure in rock specimen containing combined flaw and hole under uniaxial compression," Advances in Civil Engineering, vol. 2018, Article ID 9818250, 15 pages, 2018.

[5] X. Liu, Y. Han, D. Li et al., "Anti-pull mechanisms and weak interlayer parameter sensitivity analysis of tunnel-type anchorages in soft rock with underlying weak interlayers," Engineering Geology, vol. 253, pp. 123-136, 2019.

[6] F. Kong and J. Shang, "A validation study for the estimation of uniaxial compressive strength based on index tests," Rock Mechanics and Rock Engineering, vol. 51, no. 7, pp. 2289-2297, 2018.

[7] B. W. Isah, H. Mohamad, and N. R. Ahmad, "Multi-channel fibre bragg grating sensors for uniaxial compression test on limstone elasticity," International Journal of GEOMATE, vol. 16, no. 54, pp. 158-163, 2019.

[8] H. Li, Z. Dong, Z. Ouyang, B. Liu, W. Yuan, and H. Yin, "Experimental investigation on the deformability, ultrasonic wave propagation, and acoustic emission of rock salt under triaxial compression," Applied Sciences, vol. 9, no. 4, p. 635, 2019.

[9] C. H. Park and A. Bobet, "Crack coalescence in specimens with open and closed flaws: a comparison," International Journal of Rock Mechanics and Mining Sciences, vol. 46, no. 5, pp. 819-829, 2009.

[10] X. P. Zhou, H. Cheng, and Y. F. Feng, “An experimental study of crack coalescence behaviour in rock-like materials containing multiple flaws under uniaxial compression," Rock Mechanics and Rock Engineering, vol. 47, no. 6, pp. 1961-1986, 2014.

[11] P. Cao, T. Liu, C. Pu, and H. Lin, "Crack propagation and coalescence of brittle rock-like specimens with pre-existing cracks in compression," Engineering Geology, vol. 187, pp. 113-121, 2015.

[12] Y. L. Zhao, L. Y. Zhang, W. J. Wang et al., "Cracking and stress-strain behavior of rock-like material containing two flaws under uniaxial compression," Rock Mechanics and Rock Engineering, vol. 49, no. 7, pp. 2665-2687, 2015.

[13] X. P. Zhou, J. Z. Zhang, L. H. Yang, and Y. L. Cui, "Internal morphology of cracking of two 3-D pre-existing crossembedded flaws under uniaxial compression," Geotechnical Testing Journal, vol. 41, no. 2, pp. 329-339, 2018.

[14] X.-P. Zhou, J.-Z. Zhang, and L. N. Y. Wong, "Experimental study on the growth, coalescence and wrapping behaviors of 
3D cross-embedded flaws under uniaxial compression," Rock Mechanics and Rock Engineering, vol. 51, no. 5, pp. 1379-1400, 2018.

[15] J. Z. Zhang, X. P. Zhou, J. Y. Zhu, C. Xian, and Y. T. Wang, "Quasi-static fracturing in double-flawed specimens under uniaxial loading: the role of strain rate," International Journal of Fracture, vol. 211, no. 1-2, pp. 75-102, 2018.

[16] R. H. C. Wong, K. T. Chau, C. A. Tang, and P. Lin, "Analysis of crack coalescence in rock-like materials containing three flaws-part I: experimental approach," International Journal of Rock Mechanics and Mining Sciences, vol. 38, no. 7, pp. 909-924, 2001.

[17] C. H. Park and A. Bobet, "Crack initiation, propagation and coalescence from frictional flaws in uniaxial compression," Engineering Fracture Mechanics, vol. 77, no. 14, pp. 27272748, 2010.

[18] Q. Liu, J. Xu, X. Liu, J. Jiang, and B. Liu, "The role of flaws on crack growth in rock-like material assessed by AE technique," International Journal of Fracture, vol. 193, no. 2, pp. 99-115, 2015.

[19] Y.-H. Huang, S.-Q. Yang, and W. Zeng, "Experimental and numerical study on loading rate effects of rock-like material specimens containing two unparallel fissures," Journal of Central South University, vol. 23, no. 6, pp. 1474-1485, 2016.

[20] Y.-H. Huang, S.-Q. Yang, W.-L. Tian, W. Zeng, and L.-Y. Yu, "An experimental study on fracture mechanical behavior of rock-like materials containing two unparallel fissures under uniaxial compression," Acta Mechanica Sinica, vol. 32, no. 3, pp. 442-455, 2016.

[21] R. H. Cao, P. Cao, H. Lin, G. W. Ma, X. Fan, and X. G. Xiong, "Mechanical behavior of an opening in a jointed rock-like specimen under uniaxial loading: experimental studies and particle mechanics approach," Archives of Civil and $\mathrm{Me}$ chanical Engineering, vol. 18, no. 1, pp. 198-214, 2018.

[22] S.-Q. Yang, Y.-H. Huang, H.-W. Jing, and X.-R. Liu, "Discrete element modeling on fracture coalescence behavior of red sandstone containing two unparallel fissures under uniaxial compression," Engineering Geology, vol. 178, pp. 28-48, 2014.

[23] A. Manouchehrian, M. Sharifzadeh, M. F. Marji, and J. Gholamnejad, "A bonded particle model for analysis of the flaw orientation effect on crack propagation mechanism in brittle materials under compression," Archives of Civil and Mechanical Engineering, vol. 14, no. 1, pp. 40-52, 2014.

[24] L. N. Y. Wong and H. Q. Li, "Numerical study on coalescence of two pre-existing coplanar flaws in rock," International Journal of Solids and Structures, vol. 50, no. 22-23, pp. 3685-3706, 2013.

[25] H.-Q. Li and L. N. Y. Wong, "Numerical study on coalescence of pre-existing flaw pairs in rock-like material," Rock Mechanics and Rock Engineering, vol. 47, no. 6, pp. 2087-2105, 2014.

[26] M. Bahaaddini, G. Sharrock, and B. K. Hebblewhite, "Numerical investigation of the effect of joint geometrical parameters on the mechanical properties of a non-persistent jointed rock mass under uniaxial compression," Computers and Geotechnics, vol. 49, pp. 206-225, 2013.

[27] S. Y. Wang, S. W. Sloan, D. C. Sheng, S. Q. Yang, and C. A. Tang, "Numerical study of failure behaviour of precracked rock specimens under conventional triaxial compression," International Journal of Solids and Structures, vol. 51, no. 5, pp. 1132-1148, 2014.

[28] M. F. Marji, "Numerical analysis of quasi-static crack branching in brittle solids by a modified displacement discontinuity method," International Journal of Solids and Structures, vol. 51, no. 9, pp. 1716-1736, 2014.
[29] A. Abdollahipour, M. F. Marji, A. Yarahmadi Bafghi, and J. Gholamnejad, "Simulating the propagation of hydraulic fractures from a circular wellbore using the displacement discontinuity method," International Journal of Rock Mechanics and Mining Sciences, vol. 80, pp. 281-291, 2015.

[30] A. Abolfazl, M. F. Marji, Y. B. Alireza, and G. Javad, "DEM simulation of confining pressure effects on crack opening displacement in hydraulic fracturing," International Journal of Mining Science and Technology, vol. 26, no. 4, pp. 557-561, 2016.

[31] L. N. Y. Wong and H. H. Einstein, "Crack coalescence in molded gypsum and carrara marble: part 2-microscopic observations and interpretation," Rock Mechanics and Rock Engineering, vol. 42, no. 3, pp. 513-545, 2009.

[32] S. P. Morgan, C. A. Johnson, and H. H. Einstein, "Cracking processes in Barre granite: fracture process zones and crack coalescence," International Journal of Fracture, vol. 180, no. 2, pp. 177-204, 2013.

[33] Y. Lu, L. Wang, and D. Elsworth, "Uniaxial strength and failure in sandstone containing a pre-existing 3-D surface flaw," International Journal of Fracture, vol. 194, no. 1, pp. 59-79, 2015.

[34] S.-Q. Yang, Y.-H. Huang, and P. G. Ranjith, "Failure mechanical and acoustic behavior of brine saturated-sandstone containing two pre-existing flaws under different confining pressures," Engineering Fracture Mechanics, vol. 193, pp. 108121, 2018.

[35] B. L. A. Isaka, P. G. Ranjith, T. D. Rathnaweera, M. S. A. Perera, and W. G. P. Kumari, "Influence of long-term operation of supercritical carbon dioxide based enhanced geothermal system on mineralogical and microstructurallyinduced mechanical alteration of surrounding rock mass," Renewable Energy, vol. 136, pp. 428-441, 2019.

[36] P. T. Nhan, X. Xi, and S. Suresh, "Behaviors of crack propagation of rock-like material with different jointed thickness," International Journal of Geomate, vol. 16, no. 58, pp. 203-210, 2019.

[37] S.-Q. Yang, X.-R. Liu, and H.-W. Jing, "Experimental investigation on fracture coalescence behavior of red sandstone containing two unparallel fissures under uniaxial compression," International Journal of Rock Mechanics and Mining Sciences, vol. 63, pp. 82-92, 2013.

[38] L. Gang, X. Fu-kun, C. Qian-long, and Q. Tao, "Experimental study on acoustic emission characteristics of dry and saturated basalt columnar joints under uniaxial compression and tensile damage," Shock and Vibration, vol. 2019, Article ID 4971695, 12 pages, 2019.

[39] Q. Zhu, D. Li, Z. Han, X. Li, and Z. Zhou, "Mechanical properties and fracture evolution of sandstone specimens containing different inclusions under uniaxial compression," International Journal of Rock Mechanics and Mining Sciences, vol. 115, pp. 33-47, 2019.

[40] S.-Q. Yang, W.-L. Tian, Y.-H. Huang, Z.-G. Ma, L.-F. Fan, and Z.-J. Wu, "Experimental and discrete element modeling on cracking behavior of sandstone containing a single oval flaw under uniaxial compression," Engineering Fracture Mechanics, vol. 194, pp. 154-174, 2018.

[41] H. Lee and S. Jeon, "An experimental and numerical study of fracture coalescence in pre-cracked specimens under uniaxial compression," International Journal of Solids and Structures, vol. 48, no. 6, pp. 979-999, 2011.

[42] H. Haeri, A. Khaloo, and M. F. Marji, "Experimental and numerical analysis of Brazilian discs with multiple parallel cracks," Arabian Journal of Geosciences, vol. 8, no. 8, pp. 5897-5908, 2015. 


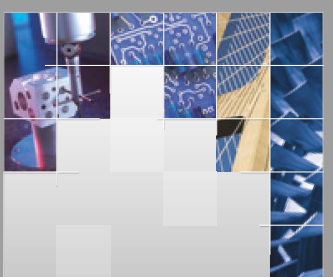

\section{Enfincering}
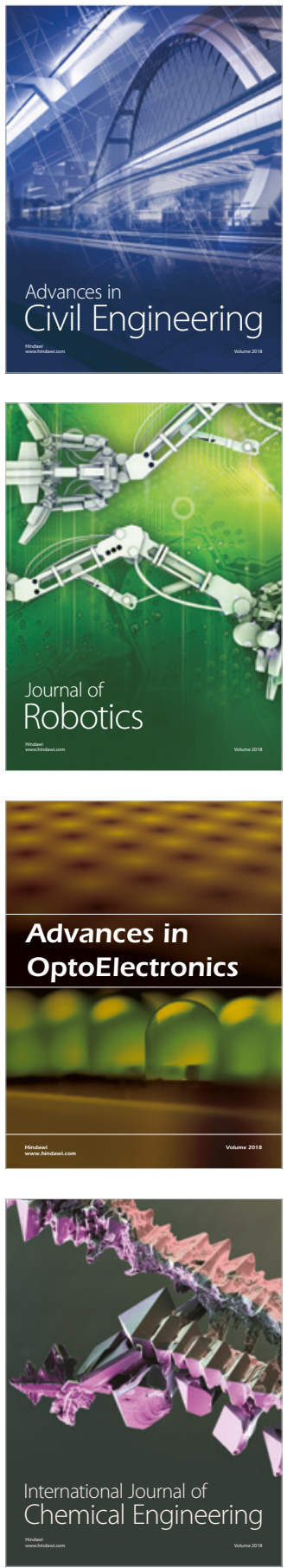

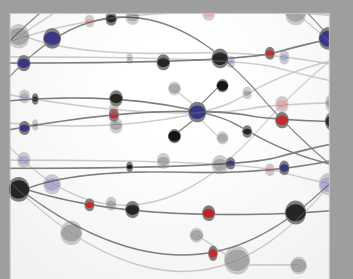

\section{Rotating \\ Machinery}

The Scientific World Journal

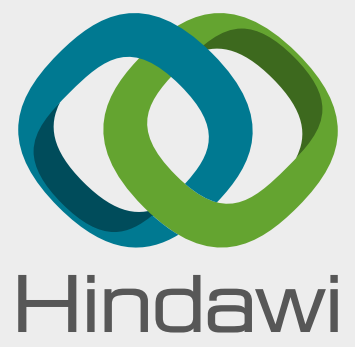

Submit your manuscripts at

www.hindawi.com
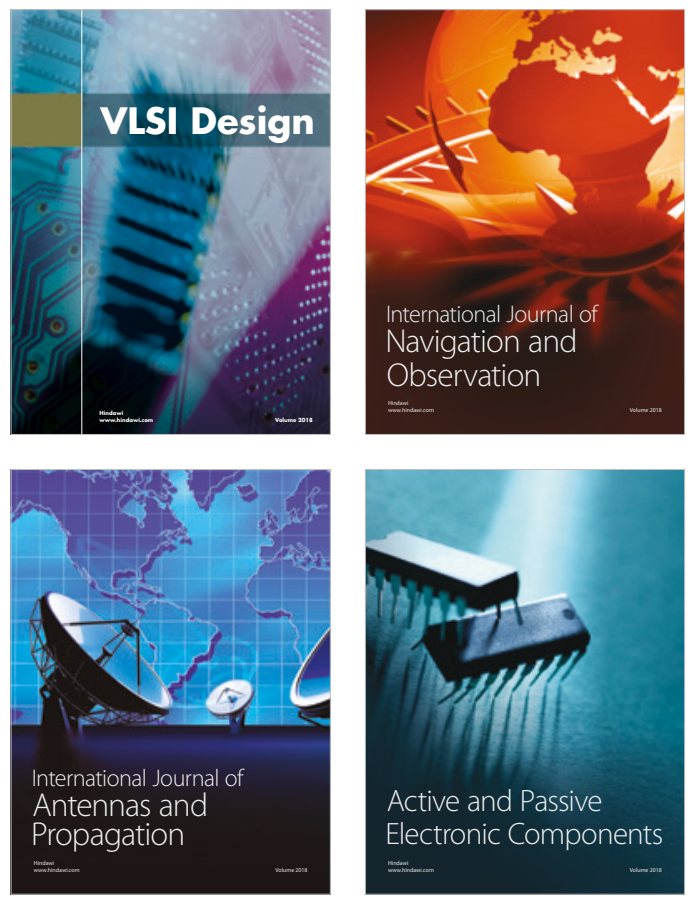
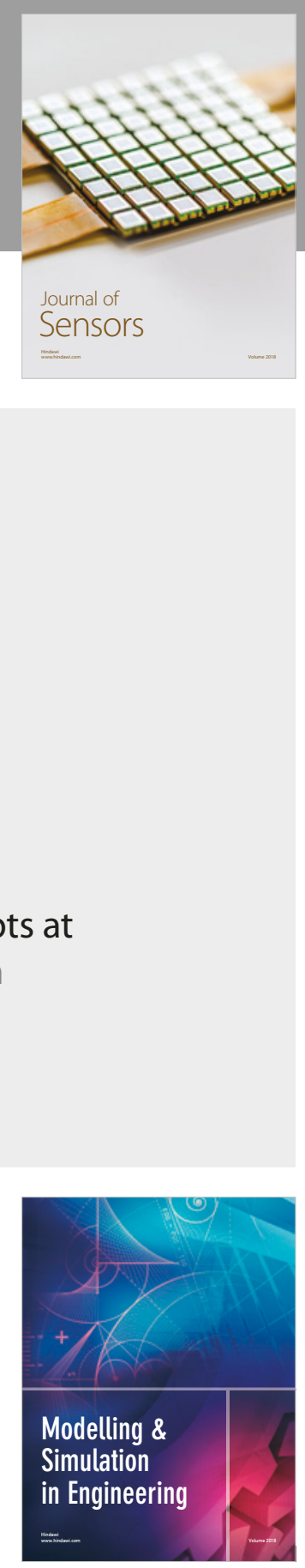

\section{Advances \\ Multimedia}
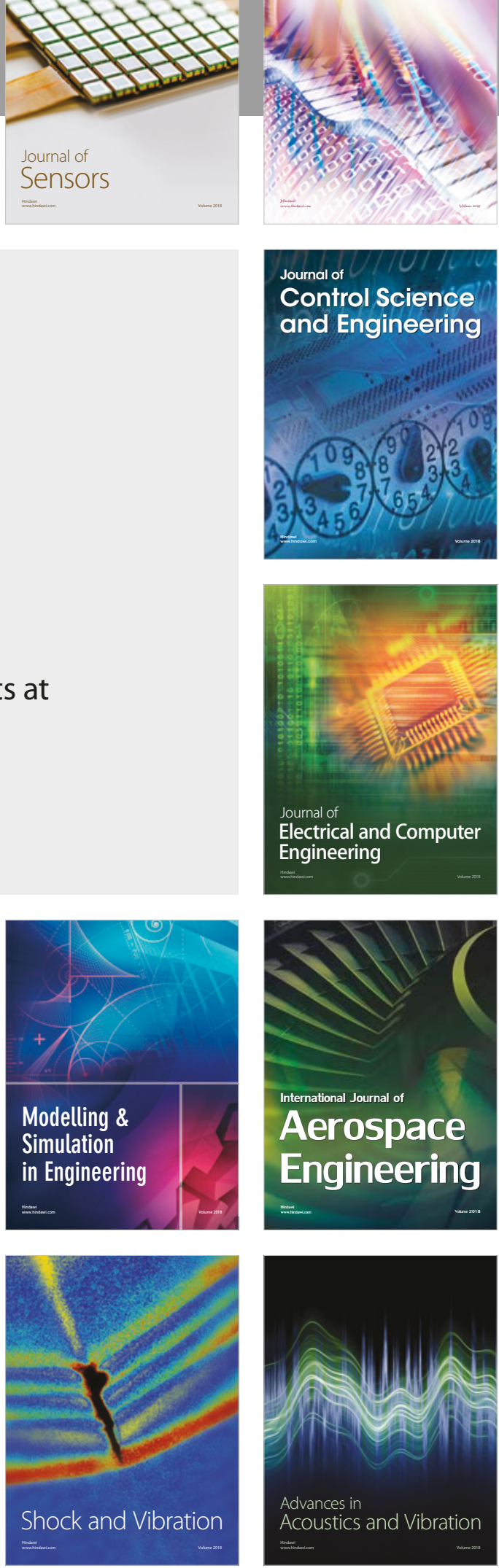